\title{
WIECE: Women Undergraduates in Electrical and Computer Engineering Summer Research Program
}

\section{Dr. Jinhui Wang, North Dakota State University}

Dr. Jinhui Wang has been an Assistant Professor in the Department of Electrical and Computer Engineering at North Dakota State University (NDSU), since Aug. 2014. His research interests include low-power, high-performance, and variation-tolerant integrated circuit design, 3D IC and EDA methodologies, and thermal issue solution in VLSI. He has more than 80 publications and 6 patents in the emerging semiconductor technologies. Dr. Wang has been with the editorial board of Microelectronics Journal, and served as the associate editor of Journal of Circuits, Systems and Computers. He has also served as the track chair for IEEE International SoC Conference 2014 (SoCC2014), the technical program committees for IEEE international conferences, including IEEE International SoC Conference 2016 (SoCC2016), 2015 (SoCC2015), 2014 (SoCC2014), 2013 (SoCC2013), 2012 (SoCC2012), IEEE International Conference on Solid-State and Integrated Circuit Technology 2016 (ICSICT2016), 2014 (ICSICT2014), IEEE International Symposium on Embedded Multicore/Many-core Systems-on-Chip 2016 (MCSoC16), 2015 (MCSoC15), and IEEE 11th International Conference on ASIC (ASICON2015).

\section{Dr. Na Gong, North Dakota State University}

Dr. Na Gong is currently an Assistant Professor in the Department of Electrical and Computer Engineering at North Dakota State University. She received her Ph.D. in Computer Science \& Engineering from University at Buffalo, The State University of New York in 2013. Dr. Gong's research interests lie in VLSI and embedded system, with an emphasis on intelligent energy-efficient data storage system. Dr. Gong has been an Associate Editor for Microelectronics Journal, Journal of Circuits, Systems, and Computers, and Mobile Computing. She has also served as track chair for IEEE International SoC Conference 2014. She has also served in technical program committees for a number of IEEE and other international conferences. Dr. Gong received 2014 NDSU Development Board of Trustee Endowment award and 2014 NDSU Centennial Endowment award. 


\section{WIECE: Women Undergraduates in Electrical and Computer Engineering Summer Research Program}

The Women Undergraduates in Electrical and Computer Engineering (WIECE) Summer Research Program was an intensive eight-week research program for women undergraduates in Electrical and Computer Engineering (ECE). Our goal was to build distinctive experiences that can propel female undergraduate students to enter graduate school.

\section{Motivation.}

ECE is one of the largest engineering disciplines and it is also one of the oldest engineering disciplines dating back to the 1880s. ECE graduates make vital contributions to modern society through their work in various areas such as computer systems, medical imaging, robotics, and wireless communications.

There have been many efforts over the last three decades to draw more women into science, technology, engineering, and mathematics (STEM) fields. While impressive gains have been made in mathematics, statistics, biology, and chemistry, the participation of women in ECE graduate programs has historically been low. According to a 2012 study conducted by the American Society for Engineering Education, the percentages of master's and doctoral degrees awarded to women in ECE are, respectively, 19.2\% and 17.7\%. At the author's department, currently 4 out of $26(15 \%)$ of master's students and 6 out of $43(14 \%)$ of doctoral students in are women. One out of eighteen faculty members in the department is women who is the author of this abstract. Therefore, the author organized WIECE attract more women into ECE graduate programs, thereby developing a more diverse science and engineering workforce. 


\section{Program Activities and Evaluation}

Supported by NDSU Development Foundation, two female undergraduate students in ECE were selected to participate in WIECE program. Computers and research space were provided to them and both of them have access to the author's research lab. The following research activities, professional development activities, and well-around activities were carried on to help WIECE students obtain research experience and become confident and motivated to pursue their graduate study:

- Research activities: Combined with students' interest and background, each WIECE student was associated with a specific research project and she performed research directly supervised by the author. One student worked on low-power logic circuit design and the other one worked on reliable SRAM schematics and layout optimization. The students attended weekly research meetings with author's graduate students and attended research discussions and presentations.

- Professional development activities: the WIECE students were engaged in many aspects of professional development, including preparing for graduate school application, paper reading skills, professional writing skills, and presentation skills;

- Meeting ECE female graduate students: to encourage WIECE students to pursue graduate study, we organized a meeting to enable the participates to learn the climate in graduate school. During the meeting, they discussed important issues with current female graduate students in ECE, including, how to balance the life and graduate school? How to succeed in graduate school? Where do graduates go after they complete their degrees?

- IC chip packaging and testing: The Center for Nanoscale Science and Engineering (CNSE) provides IC testing resources includes 77,000 square feet of clean room, laboratory and engineering spaces. CNSE conducts electronic miniaturization research and fabrication in the Class 10,000 and 100 cleanrooms. With the author's graduate students, the WIECE students visited the Center for Nanoscale Science and Engineering (CNSE) and worked there on Integrated Circuits (IC) chip packaging and testing. Figures 1 and 2 show the packaged chips at CNSE. 


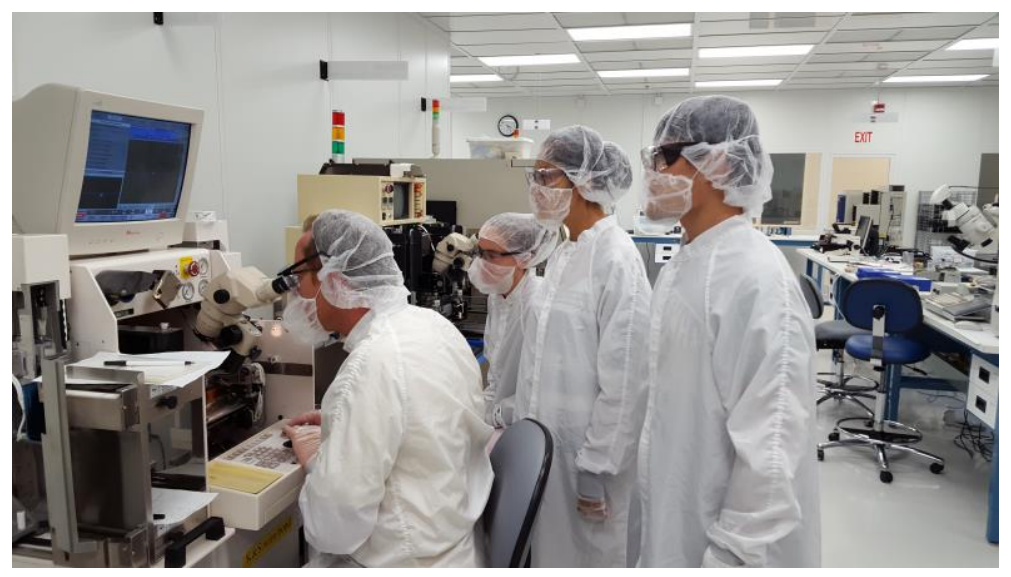

(a)

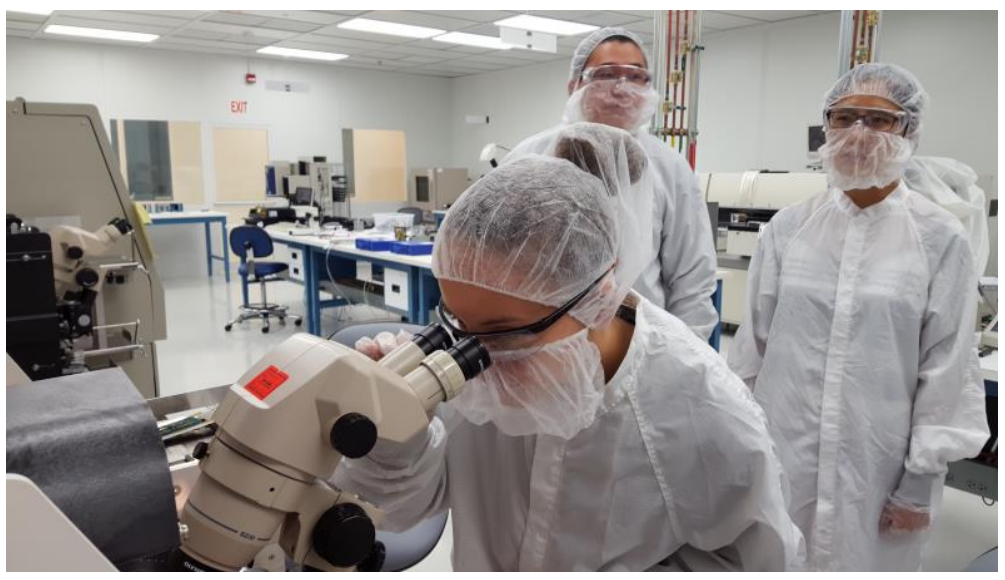

(b)

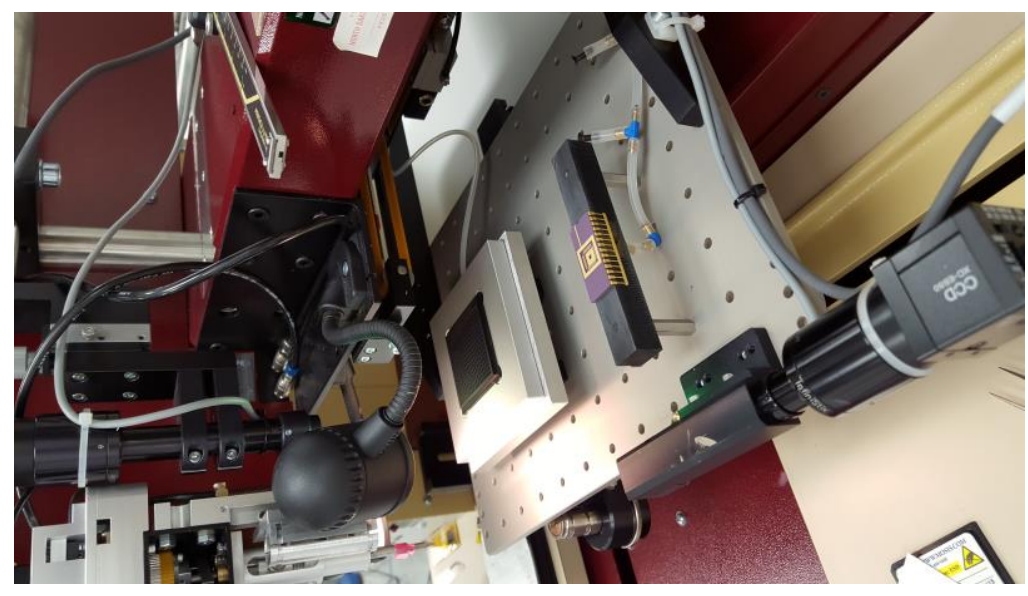

(c)

Figure 1: WIECE students worked at CNSE on IC Chip Packaging and Testing. 


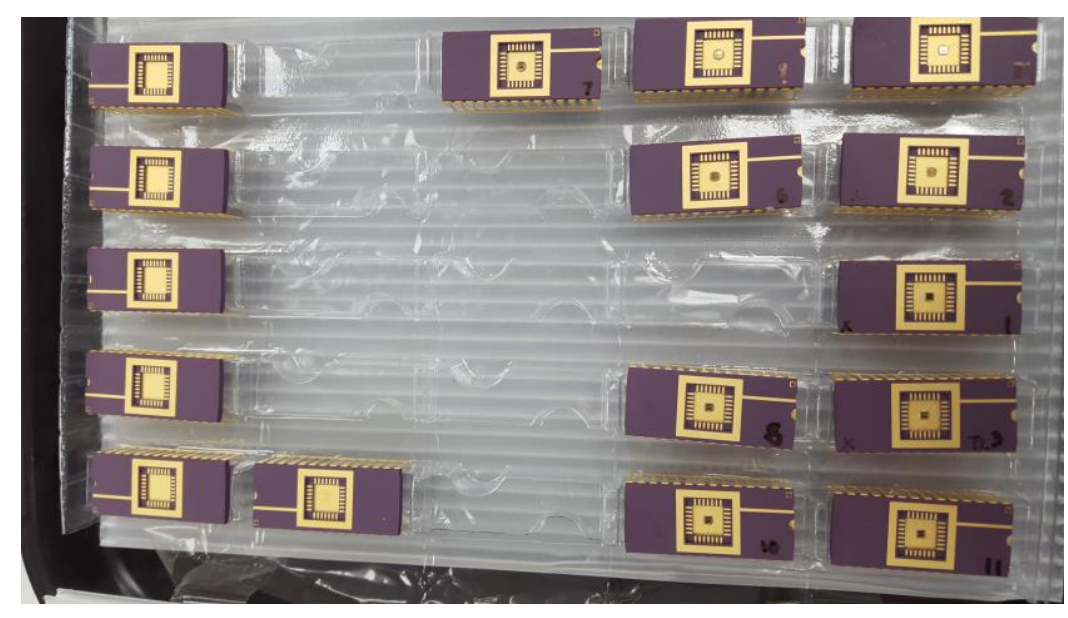

Figure 2: The Packaged Chip.

\section{Evaluation}

Student surveys were conducted at the end of the program. The participants rated the WIECE favorably. They both agreed that WIECE helped them have a better understanding of what graduate school entails, strengthen their academic confidence and interest in graduate study. They both continue their research in the author's research lab in the fall semester 2015 and spring semester 2016.

\section{Conclusion}

WIECE provided research opportunities for women undergraduates in ECE. WIECE2015 is a pilot attempt and opportunities exist for increasing participation and refining overall program activities based on the survey results. 